\title{
IPI: uma abordagem constitucional
}

\author{
IPI: a constitutional approach
}

\section{Guilherme Luis Muramatsu Pereira ${ }^{1}$ Larissa Martins de Andrade ${ }^{2}$}

\begin{abstract}
Resumo
O Imposto sobre Produtos Industrializados é de competência da União e está previsto no Art. 153, IV da Constituição Federal de 1988. 0 tributo destaca-se por seu caráter extrafiscal, não-cumulativo e seletivo. Diante disso, ocupa uma situação peculiar no ordenamento jurídico brasileiro. Tais peculiaridades tornam indispensável a análise do tributo sob uma perspectiva principiológica, inserida em um contexto constitucional. Desempenha importante função reguladora da economia nacional, envolvendo ditames político-sociais na defesa do mercado interno em relação à concorrência internacional. É constantemente objeto de contenda nos tribunais, envolvendo interesses bilionários. 0 presente estudo se dedica a demonstrar algumas violações decorrentes de sua aplicação e seus reflexos na estrutura econômica sobre a qual foi organizado o Estado.
\end{abstract}

Palavras Chave: Imposto sobre Produtos Industrializados; Não-cumulatividade; Anterioridade; Extrafiscalidade; Seletividade; Benefício fiscal; Crédito-prêmio.

\begin{abstract}
The Excise Tax is the responsibility of the Union and is laid down in Article 153, IV of the Constitution of 1988. The toll stands out for its character extrafiscal, cumulative and non-selective. Therefore, occupies a peculiar situation in Brazilian law. Such peculiarities make it essential to analyze the tax on a principled perspective, embedded in a constitutional context. Plays an important regulatory role of the national economy, political and social dictates involving the defense of the internal market in relation to international competition. It is constantly the object of contention in the courts, involving billionaire interests. This study is dedicated to show some violations resulting from its implementation and its impact on the economic structure upon which the State was organized.
\end{abstract}

Keywords: Excise Tax, Non-cumulative; before; extrafiscal; Selectivity; tax benefit; Credit award.

\footnotetext{
${ }^{1}$ Graduando no curso de Direito na Universidade Estadual de Londrina (UEL) e de Ciências Contábeis na Pontifícia Universidade Católica do Paraná (PUC-PR).

${ }^{2}$ Graduanda no curso de Direito na Universidade Estadual de Londrina (UEL).
} 


\section{Introdução}

Antes de abordar especificidades do Imposto sobre Produtos Industrializados - IPI bem como de qualquer outra espécie tributária, faz-se necessário uma análise de sua obediência irrestrita à Constituição Federal de 1988. Fonte inaugural do ordenamento jurídico, é a Lei Maior que fornece os fundamentos jurídicos os quais permitirão estabelecer os direitos e deveres daqueles inseridos na relação jurídico-tributária, dispondo sobre a regra-matriz, arquétipo genérico de cada tributo, norma-padrão de incidência de cada uma das figuras jurídicas ali preconizadas.

o Direito Tributário é revestido de dignidade constitucional, uma vez que foi minuciosamente tratado pelo constituinte originário. Representa, pois, fonte de receita para o Poder Público decorrente de sua ingerência no patrimônio dos particulares (é constrição ao direito de propriedade) e confere aos contribuintes e responsáveis direitos e garantias fundamentais.

Conseqüentemente, o legislador federal não pode esquivar-se das diretrizes impostas à materialidade do tributo. 0 Imposto sobre Produto Industrializado incidirá sobre produtos industrializados (Art. 153, IV). Desta assertiva depreende-se o objeto sobre o qual a hipótese de incidência irá relacionar-se.

É necessário se fazer uma análise sistêmica de todos os princípios a ele inerentes. Conforme leciona Paulo de Barros (2007, p. 158), "onde há princípios existem valores de magnitude para o sistema, e tais valores vem sempre acompanhados de elevado grau de indeterminação". Cabe ao intérprete auferir o real sentido da norma constitucional para evitar contradições com outros dispositivos.

Indaga-se o papel desempenhado pelas ficções jurídicas criadas pelo legislador no que tange à pessoalidade da regra-matriz de incidência, a desproporcionalidade das alíquotas quando da elaboração das Tabelas de Incidência do Imposto de Produtos Industrializados (TIPI) e o desrespeito à não-cumulatividade à ocasião de concessão de créditos presumidos para as empresas exportadoras, ferindo o princípio da isonomia e prejudicando 0 efeito das leis de incentivo fiscal. 0 presente estudo versará sobre tais questionamentos. 


\section{Regra-matriz: análise do critério pessoal}

A Constituição outorga à União competência para instituir o Imposto sobre Produtos Industrializados (Art. 153, IV). Diante disso, o legislador federal somente poderá trazer para a relação como sujeito passivo pessoa "vinculada ao cerne do IPI, ou seja, quem mantenha relação pessoal e direta com a respectiva materialidade" (DE M ELO, 2001, p. 426), e que, voluntariamente, realize o fato imponível. Todavia, o tributo em análise abrange não somente o fato da própria industrialização, como também a importação de produtos industrializados. Havia, ainda, uma terceira hipótese, que onerava arrematações em leilões que, no entanto, encontra-se revogada.

Não obstante, assim dispõe do Art. $9^{\circ}$ do Decreto de n. 4.544 de 26 de dezembro de 2002, o atual Regulamento do Imposto sobre Produtos Industrializados:

Art. 9o Equiparam-se a estabelecimento industrial:

I - os estabelecimentos importadores de produtos de procedência estrangeira, que derem saída a esses produtos (Lei № 4.502, de 1964, art. 4으, inciso I);

II - os estabelecimentos, ainda que varejistas, que receberem, para comercialização, diretamente da repartição que os liberou, produtos importados por outro estabelecimento da mesma firma; [...]

E outros dez incisos, todos os quais equiparam estabelecimentos comerciais a industriais para finalidades fiscais, pessoas estranhas às atividades atinentes à industrialização de produtos. Constitui referido dispositivo ficção jurídica no ordenamento tributário brasileiro, causando verdadeira insegurança entre os jurisdicionados.

0 princípio da capacidade contributiva, albergado no Art. $145, \S 1^{0}$ da $\mathrm{CF} / 88$, não permite a distribuição de cargas tributárias estranhas à hipótese de incidência. Determinado montante somente deveria ser arcado por parte de algumas pessoas com seu patrimônio relativamente às materialidades tributárias a que estejam interligadas, motivo pelo qual somente quem industrializa é que deveria sujeitar-se ao IPI.

A circunstância de que a Lei Maior não indicou pessoa que figurasse como devedora do IPI não permite que o Código Tributário Nacional (Art. 46, I) ou a RIPI possa indicar pessoa estranha à industrialização de produtos.

Semelhante situação ocorre quando antecipa-se o momento da exigência do 
recolhimento do imposto - a "responsabilidade tributária por fato futuro" (CARRAZA, 2005, p. 418) - ou, como outros preferem, substituição tributária "pra frente", uma vez que ainda nem ocorrera a hipótese de incidência, sendo possível que nem mesmo venha a acontecer. Não há industrialização e não há operação jurídica.

Preceitua o professor José Eduardo Soares de Melo (2001, p. 427) sobre o tema:

Inaceitáveis os mecanismos engendrados pelo legislador nacional com a finalidade de obter a liquidação do tributo por pessoas estranhas à realização da industrialização, em razão do que o quadro de sujeição passiva não pode ser ampliado de modo a permitir à União a exigência tributária fora dos parâmetros constitucionais.

Extrapolam, em conclusão, a delimitação constitucional da regra-matriz de incidência. Essa violação não encontra limites, visto que o tributo constitui exceção ao princípio da estrita legalidade, ficando ao alvedrio do Chefe do Poder Executivo alterar os dispositivos atinentes ao tributo sob análise.

\section{Princípio da seletividade}

No Art. $153, \S 3^{\circ}, 1$, da Carta Magna está evidenciado o princípio da seletividade. 0 IPI será seletivo em função da essencialidade do produto no qual estiver incidindo. Ante 0 critério da essencialidade que foi o escolhido para aventar o critério quantitativo da relação jurídico-tributária, importa afirmar que as alíquotas dos bens sobre os quais estas incidirão serão inversamente proporcionais às suas necessidades para o consumo popular.

0 termo seletividade é considerado, por alguns, aplicação prática do princípio constitucional da capacidade contributiva através da progressão de alíquotas. Quanto mais supérfluo for considerado determinado produto, maior será sua alíquota. Desta forma, suaviza-se o impacto tributário suportado pelos bens consumidos pelas diferentes classes, como adequação do produto à vida do maior número de habitantes do país.

Tal interpretação, todavia, é consideravelmente restrita, visto que o critério para se cotejar tal essencialidade não passa de uma simples presunção, por vezes, até, inexplicável. Seria compreensível o fato de que cigarros que contém tabaco possuam alíquota de $330 \%$ (trezentos e trinta por cento), enquanto que cigarros feitos à mão são tributados com alíquota de apenas 30\% (trinta por cento)? Afinal, ambos não desempenham finalidades 
semelhantes e são destinados a um mesmo mercado?

Assim, entender-se-ia como legítima apenas a presunção quando fixada por critérios razoáveis.

Apesar de alguns equívocos por parte do legislador, ressalta-se que a seletividade não é mera recomendação constitucional - deve ser obedecida, invariavelmente.

Com 0 intuito de atender o princípio da seletividade, faz-se mister que haja uma classificação, em primeiro lugar, dos produtos e mercadorias, para que, de acordo com 0 grau de essencialidade, haja uma diferenciação das alíquotas, tributando-os de forma diversa.

No ordenamento pátrio, tal classificação encontra-se na Tabela de Incidência do Imposto sobre Produtos Industrializados (TIPI), trazida pelo Decreto de n. 6.006/2006, dividida em Seções, Capítulos, subcapítulos, posições, subposições, itens e subitens (Lei no 4.502, de 1964, Art. 10). Ali estão arrolados todos os produtos e suas respectivas alíquotas previstas para a hipótese de incidência do Imposto sobre Produto Industrializado.

\section{Princípio da extrafiscalidade}

O Art. 97, IV do CTN assim enuncia:

Art. 97 - Somente a Lei po de estabelecer:

IV - a fixação da alíquota do tributo e da sua base de cálculo, ressalvado o disposto nos Arts. 21, 26, 39, 57 e 65.

0 aludido Artigo 21 do Código Tributário Nacional define que, nos limites da lei, 0 Poder Executivo poderá alterar as alíquotas ou as bases de cálculo do imposto, a fim de ajustá-lo aos objetivos da política cambial e do comércio exterior. Uma interpretação sistêmica em consonância com a Emenda Constitucional de n. 42 de 2003, fruto de reivindicações dos contribuintes ${ }^{3}$, permite inferir que, respeitado o regime de noventena a que está sujeito o IPI, poderá a Administração manejar o tributo de forma a coaduná-lo com

\footnotetext{
${ }^{3}$ Outrora, as freqüentes alterações de alíquotas do IPI por meio de Decreto do Poder Executivo, com vigência a partir da própria data de sua publicação no Diário Oficial da União causavam grandes transtornos e prejuízos a industriais, importadores e demais contribuintes desse imposto, pois eram comuns os casos de restituição ou complemento do imposto devido e falta de tempo hábil para adaptar sistemas eletrônicos, planilhas de custos, preços de venda e etc.
} 
os objetivos políticos e econômicos do país, à revelia do Princípio da Anterioridade. Conseqüência direta desse fato é que as alterações poderão ser realizadas através de Decretos do Chefe do Executivo Federal, excepcionando, por conseguinte, o Princípio da Legalidade (estrita legalidade).

Observa-se que o IPI pode ser utilizado como medida incentivadora a determinadas condutas. São balizas constitucionais de indelével importância para a Administração em incentivar ou não determinado comportamento do mercado, incidindo de maneira objetiva no domínio econômico, sem a necessidade de se recorrer aos órgãos internacionais, tais como o BIRD e o FM I.

Daí depreende-se a natureza extrafiscal do tributo, uma vez que além de servir como arrecadação tributária federal, é instrumento de controle e intervenção de setores da economia nacional.

Por meio do Imposto de Importação, do Imposto sobre Operações Financeiras e pelo Imposto sobre Produtos Industrializados, é possível dispor de ferramentas para intervir no domínio econômico, de forma a tentar manter capital dentro das fronteiras de seu país e/ ou proteger o mercado da concorrência externa.

"A extrafiscalidade é o princípio ontológico da tributação e epistemológico do Direito Tributário" (GOUVÊA, 2006, p. 80). Desta assertiva aduz-se que a extrafiscalidade justifica juridicamente a atividade de tributar estatal e a impele, com a finalidade de tornar realidade os valores constitucionalmente albergados, sendo orientada por políticas públicas delimitadas pelas garantias fundamentais expressas no estatuto do contribuinte.

\section{Princípio da não-cumulatividade}

0 princípio da não-cumulatividade no Imposto sobre Produtos Industrializados encontra referência expressa na Constituição Federal, em seu Artigo 153, §3ํ, II, que dispõe:

\section{Art. $153(\ldots)$}

$\S 300$ imposto previsto no inciso IV:

(...)

II - Será não-cumulativo, compensando-se o que for devido em cada operação com o montante cobrado nas anteriores. 
Nessa perspectiva, deve-se interpretar o princípio em análise como regra de conduta, constituída de significativo conteúdo axiológico, indispensável à harmonia e organização sócio-econômica do Estado.

A partir das orientações constitucionais, e também daquelas fornecidas pelo Código Tributário Nacional (Art. 49), define-se a não-cumulatividade como um sistema de compensações que faz incidir o tributo sobre o valor agregado dos fatos jurídicos tributários. Assim, os contribuintes aproveitam créditos das respectivas entradas e têm contra si débitos das saídas dos produtos objeto das incidências prescritas na legislação.

Deste modo, o mecanismo em questão destina-se a minimizar o impacto do tributo sobre os preços dos produtos comercializados, evitando-se o "efeito em cascata". Nesse sentido, esclarece José Eduardo Soares de M elo (2004, p. 101).

Caso fosse suprimida, a cumulatividade tributária geraria um custo artificial indesejável (...), totalmente desvinculado da realidade da produção e comercialização. Isto, evidentemente, oneraria sobremaneira o custo de vida da população. De outra parte, encareceria também o processo produtivo e comercial, reduzindo os investimentos (...) em face do aumento de custos ocasionado por esse artificialismo tributário oriundo da cumulatividade.

É importante esclarecer que, ao disciplinar a sistemática da não-cumulatividade, não foi estabelecido um confronto entre o imposto incidente sobre cada mercadoria e sua respectiva saída. Ao contrário: o que ocorre é um procedimento aritmético-contábil de apuração total do imposto incidente sobre as entradas e sobre as saídas dos produtos. Se assim não fosse, a aplicação do referido princípio seria inviável.

Além disso, cabe destacar, como bem o faz Kiyoshi Harada (2004, p. 96) que:

A técnica da não-cumulatividade pretende evitar a superposição de incidências sobre uma série de operações que visam completar um único ciclo econômico de produção. Esta superposição é evitada através do mecanismo de crédito e débito de imposto pago e a pagar quando feito generalizadamente.

E, diferentemente do ICMS, não há qualquer restrição para a não-cumulatividade relacionada ao IPI. Conseqüentemente, será compensado o montante do imposto inerente à 
operação anterior, ainda que se trate de aquisição de produtos beneficiados pela isenção, alíquota zero ou não tributação. Isto porque, como bem esclarece a jurista Valéria Gutjahr (2003, p. 388):

0 direito ao crédito se perfaz com total independência da circunstância de nascer ou não a obrigação tributária. Há direito ao crédito porque o imposto é não cumulativo e a índole não cumulativa advém de mandamento constitucional. 0 equivoco está em pensar que o direito ao crédito decorre da incidência da norma jurídica tributária. Desta surge a obrigação do imposto, que é direito subjetivo de que está investido a Fazenda Pública e não o contribuinte.

Pela regra da não-cumulatividade, ao fim de cada período (usualmente mensal), o contribuinte é obrigado a proceder à operação do montante do imposto correspondente aos débitos pelas suas operações de saídas de produtos industrializados, e do montante de créditos correspondentes às operações anteriores, de bens que ingressaram no seu estabelecimento. Do confronto entre ambos (débitos e créditos), resultará um saldo. Caso desse confronto resulte importância superior a título de débito, o contribuinte deverá recolher tal valor, nas condições e prazos estipulados; todavia, caso o saldo seja superior a título de crédito, o contribuinte deverá transferi-la para o período posterior.

Evidente que se está, portanto, diante de um princípio constitucional de natureza tributária, que não pode ser alterado ou suprimido (sem que isso provoque expressivo abalo na ordem constitucional vigente). Implica em respeito e resguarda do

legislador e obrigação do sujeito passivo da relação. Como bem disse José Eduardo Soares de M elo (2004, p. 101):

Aplicar o princípio da não-cumulatividade não é mera sugestão do legislador constituinte. Antes, pelo contrário, trata-se de um comando indisponível, que vincula 0 contribuinte e o Estado, para a manutenção da ordem econômica instituída no Texto Supremo (...). o dispositivo constitucional manda, impõe, determina que se faça a apropriação dos créditos para, com eles, proceder-se à compensação.

Ainda inserido na perspectiva constitucional do princípio da não-cumulatividade, muito pode ser questionado quanto à impossibilidade da compensação - situação de evidente desrespeito a diversos preceitos contidos na Carta Magna. É o que se passa com as 
empresas exportadoras hodiernamente, que são impossibilitadas de compensar seus créditos, uma vez que o Imposto sobre Produtos Industrializados não incide sobre exportações, gerando um saldo credor reiterado.

Crédito-prêmio

0 crédito-prêmio consiste em um incentivo fiscal às exportações de produtos industrializados, instituído pelo Decreto-Lei 491/69 - dispunha que as empresas fabricantes e exportadoras de produtos manufaturados gozariam de um crédito tributário advindo das vendas desses produtos para o exterior.

Assim, possível seria a realização da compensação (garantida pelo princípio da nãocumulatividade), ainda que sobre os produtos destinados à exportação não incidisse o IPI as empresas exportadoras deduziriam esse crédito do valor das operações realizadas no mercado interno.

Em 1979, o Decreto de n. 1.658 dispôs que o benefício deveria ser extinto gradativamente, até 0 ano de 1983. Todavia, antes que isto ocorresse, em 1981, outro Decreto (n. 1894 de 1981) assegurou sua continuidade. Após a promulgação da Constituição Federal, discussões a respeito da validade ou não do crédito-prêmio continuaram acirradas. De acordo com o Art. 41 do Ato das Disposições Constitucionais Transitórias, os incentivos setoriais seriam extintos caso não fossem ratificados em dois anos. 0 Imposto sobre Produtos Industrializados, contudo, não pôde ser abrangido por tal disposição, já que possui caráter geral, não setorial.

No ano de 1992, a Lei de n. 8.402 restabeleceu a vigência do crédito-prêmio. A insegurança legislativa em relação à matéria gerou reflexos na jurisprudência. Após anos de concessão do benefício, em discussão no Superior Tribunal de Justiça, no ano de 2007, 0 mesmo decidiu de forma contrária ao entendimento até então prevalente: deu o benefício como extinto desde 1990, em consonância com o Artigo 41 da ADCT.

Não conceder o crédito-prêmio é um desestímulo à atividade exportadora e tornam inócuos os incentivos que visam fomentá-la. Como se não bastasse, em 2002 o Secretário da Receita Federal, através da Instrução Normativa de n. 226, determinou que fosse liminarmente indeferido o pedido de restituição ou ressarcimento cujo crédito tivesse por base o "crédito-prêmio". De evidente inconstitucionalidade, com óbvio desrespeito ao direito de petição e devido processo legal. 
É inimaginável compreender, à luz dos princípios constitucionais e da imperiosidade de suas aplicações, a violação do direito ao crédito-prêmio. Ademais, ante a extrafiscalidade do tributo, é sobremaneira inalcançável tal entendimento.

Assevera-se que, no ano de 2003, no "Anexo de Riscos Fiscais" da Lei de Diretrizes Orçamentárias, em análise dos principais riscos a que as contas públicas estavam sujeitas, foram citadas as ações que envolviam o crédito-prêmio do IPI como uma das maiores possibilidades de riscos de dívida, na categoria de passivos contingentes, isto é, dívidas cuja existência depende de fatores imprevisíveis. Isto porque as ações relativas ao tema envolvem valores que chegam a centenas de milhões de reais.

A discussão a respeito da possibilidade ou não de concessão do crédito-prêmio, todavia, ainda aguarda decisão do Supremo Tribunal Federal.

\section{Conclusão}

O Imposto sobre Produtos Industrializados ocupa a terceira posição do ranking dos tributos que mais arrecadam para a União - atrás apenas do IR e da COFINS - arrecadação recorde no mês de maio de 2008 de 50,431 bilhões de reais (BRASIL, 2008).

Diante da magnitude do imposto em análise, resta-se imprescindível e urgente a busca por novas alternativas de forma a viabilizar a aplicação dos preceitos constitucionais; quais sejam os da não-cumulatividade, extrafiscalidade, seletividade, dentre outros.

Enquanto os embates persistirem insolúveis; legislação e jurisprudência não alcançarem uniformidade e coesão; Estado e contribuinte não se conscientizarem de seus deveres e obrigações em mútua colaboração; não se logrará uma célere e efetiva solução das desigualdades e do cumprimento dos objetivos pretendidos pela Constituição.

"Quanto mais conforme a expectativa é uma legislação, menos indispensável é 0 recurso à autoridade para fazer respeitá-Io" (PERELM AN, 2002, p. 428). Em outras palavras, quanto mais arraigado o sentimento de Justiça na relação estabelecida entre o Estado e seus jurisdicionados, tanto maior será a disposição das pessoas a cumprirem estas normas. Significa que quanto maior o respeito pela autoridade ao direito dos cidadãos, maior será a disposição dos cidadãos para cumprirem suas obrigações.

Disposições de constitucionalidade duvidosa obstam o surgimento de um sistema

REVISTA DE DIREITO PÚBLICO, LONDRINA, V. 4, N. 1, P. 114-124, JAN/ ABR. 2009. 
tributário efetivo e de um contribuinte consciente. As dificuldades se manifestam tanto na tentativa de repressão da evasão fiscal, como, por outro lado, pela ausência de limites do poder de tributar do Estado.

\section{Referências}

BRASIL. Secretaria da Receita Federal. Gráfico das receitas com arrecadação. Disponível em http://www.receita.gov.br/graficos2008/arrecadac\%a\&o/maio.htm. Acessado em: 30 de outubro de 2008.

CARRAZZA, Roque Antonio. Curso de Direito Constitucional Tributário. 20a ed. Rev., amp. e atu. São Paulo: Malheiros, 2005.

CARVALHO, Paulo de Barros. Curso de direito tributário. 19a ed. São Paulo: Saraiva, 2007. DE M ELO, José Eduardo Soares. IPI. In: M ARTINS, Ives Gandra (coordenador). Curso de Direito Tributário. 8a ed. São Paulo: Saraiva, 2001.

GOUVÊA, M arcus de Freitas. A extrafiscalidade no direito tributário. Belo Horizonte: Del Rey, 2006.

GUTJAHR, Valéria. Direito ao Crédito de IPI na aquisição de insumo ou na saída de produto isento, imune, sujeito à alíquota zero ou não tributado. In: PEIXOTO, M arcelo M agalhães (coordenador). IPI - Aspectos Jurídicos Relevantes. São Paulo: Quartier Latin, 2003.

HARADA, Kiyoshi. IPI e alíquota zero. Disponível em http://www.fiscosoft.com.br / mainindex.php?home_artigos $\& m=\_\& n x \_=\&$ viewid=126447.Acesso em 19.11.2008.

MELO, José Eduardo Soares de. LIPPO, Luiz Francisco. A não-cumulatividade tributária (ICMS, IPI, PIS e Cofins). São Paulo: Dialética, 2004.

PERELM AN, Chaïm. Ética e Direito . Tradução de M aria Ermantina Galvão. São Paulo : Martins Fontes, 2002. 